\title{
The metabolic syndrome and severity of diabetic retinopathy
}

This article was published in the following Dove Press journal:

Clinical Ophthalmology

28 April 2015

Number of times this article has been viewed

\section{John J Chen ${ }^{1,2, *}$ \\ Lucas J Wendel ${ }^{1,3, *}$ \\ Emily S Birkholz' \\ John G Vallone ${ }^{4}$ \\ Anne L Coleman ${ }^{5,6}$ \\ $\mathrm{Fei} \mathrm{Yu}^{7}$ \\ Vinit B Mahajan ${ }^{1,3,8}$}

'Department of Ophthalmology and Visual Sciences, University of lowa, lowa City, IA, USA; ${ }^{2}$ Mayo Clinic,

Rochester, MN, USA; ${ }^{3}$ Vitreoretinal Service, University of lowa, lowa City, IA, USA; ${ }^{4}$ Department of Pathology, University of Southern California, ${ }^{5}$ Department of Ophthalmology, ${ }^{6}$ Department of Epidemiology, School of Public Health, ${ }^{7}$ Department of Biostatistics, University of California, Los Angeles, CA, USA; ${ }^{8}$ Omics Laboratory, University of lowa, lowa City, IA, USA

*These authors contributed equally to this work
Correspondence: Vinit B Mahajan Vitreoretinal Service, Department of Ophthalmology and Visual Sciences, University of lowa, 200 Hawkins Drive, lowa City, IA 52242, USA

$\mathrm{Tel}+\mathrm{I} 3193563185$

Fax + I 3193560363

Email vinit-mahajan@uiowa.edu
Background: While metabolic syndrome has been strongly implicated as a risk factor for macrovascular diseases, such as stroke and cardiovascular disease, its relationship with microvascular diseases, including diabetic retinopathy, has been less defined. The purpose of this pilot study was to investigate the association between metabolic syndrome and the presence and severity of diabetic retinopathy.

Methods: A retrospective case-control chart review at the University of Iowa ophthalmology and primary care clinics included 100 patients with proliferative diabetic retinopathy (PDR), 100 patients with nonproliferative diabetic retinopathy (NPDR), 100 diabetic patients without diabetic retinopathy, and 100 nondiabetic patients who were randomly selected. Using the International Diabetes Foundation definition, the prevalence of metabolic syndrome and the number of components of metabolic syndrome were compared among these groups.

Results: The prevalence of metabolic syndrome in patients with diabetes was $69.3 \%$, which was significantly higher than that in patients without diabetes $(27 \% ; P<0.0001)$ (odds ratio $[\mathrm{OR}]=6.28 ; 95 \%$ confidence interval $[\mathrm{CI}]: 3.76-10.49 ; P=0.0004)$. However, there was no significant difference in the prevalence of metabolic syndrome between diabetics with and without diabetic retinopathy, with rates of $67.5 \%$ and $73 \%$, respectively $(P=0.36)(\mathrm{OR}=0.77$; 95\% CI: $0.45-1.32 ; P=0.34)$. In addition, there was no significant difference between the PDR and NPDR groups, with rates of $63 \%$ and $72 \%$, respectively $(P=0.23)(\mathrm{OR}=0.70 ; 95 \%$ CI: $0.38-1.30 ; P=0.26$ ).

Conclusion: The metabolic syndrome was highly prevalent in patients with diabetes, but it was not associated with the presence or severity of retinopathy.

Keywords: metabolic syndrome, diabetes, diabetic retinopathy, obesity, BMI, hypertension

\section{Introduction}

There are an estimated 366 million people with diabetes worldwide, the majority of whom will ultimately develop diabetic retinopathy. ${ }^{1,2}$ Diabetic retinopathy is the leading cause of blindness in young to middle-aged adults in the developed world. Therefore, it is important to address modifiable risk factors to prevent sight-threatening diabetic retinopathy. Numerous population-based studies have examined the prevalence of diabetic retinopathy and have attempted to identify risk factors for its development and progression. ${ }^{3-9}$ These studies have yielded conflicting results. Diabetes duration, higher average blood glucose, insulin therapy, hypertension, male sex, obesity, and albuminuria have all been identified as independent risk factors for the development of retinopathy. ${ }^{5,7,8}$ However, other studies that refute many of these risk factors exist. ${ }^{7,10}$

The metabolic syndrome refers to the co-occurrence of elevated plasma glucose, excess abdominal adiposity, elevated blood pressure, and dyslipidemia. ${ }^{11}$ The clustering of these risk factors is believed to act synergistically to cause various vascular 
morbidities. This increasingly recognized and increasingly prevalent syndrome is associated with a significantly increased risk of cardiovascular disease and type 2 diabetes. ${ }^{12-15}$ Population studies show that metabolic syndrome is common, even among children and adolescents. ${ }^{16,17}$

While metabolic syndrome has been strongly implicated as a risk factor for macrovascular diseases such as stroke and cardiovascular disease, its relationship with microvascular diseases, including diabetic retinopathy, has been less defined. ${ }^{11,18}$ There are currently studies that suggest an association between metabolic syndrome and diabetic retinopathy, ${ }^{13,19,20}$ and others that demonstrate no significant increase in diabetic retinopathy among patients with metabolic syndrome compared to diabetic patients without metabolic syndrome. ${ }^{21,22}$ None of these studies distinguished between diabetic retinopathy severity, which could account for the different findings if proliferative retinopathy had different representations, for example. Current treatment of diabetes and diabetic retinopathy include annual eye examinations, laser photocoagulation, intravitreal injections of anti-vascular endothelial growth factor drugs or steroids, and vitreoretinal surgery. If metabolic syndrome was strongly associated with the development or severity of diabetic retinopathy, modifying these risk factors could be advocated to alter the disease process. Therefore, the purpose of this study was to determine whether metabolic syndrome was more common in individuals with diabetic retinopathy and whether metabolic syndrome was more prevalent in those with more severe retinopathy.

\section{Materials and methods}

The study protocol was approved by the Institutional Review Board for Human Subjects Research at the University of Iowa, and the study adheres to the tenets set forth in the Declaration of Helsinki.

\section{Study population}

A retrospective chart review identified patients with proliferative diabetic retinopathy (PDR) and nonproliferative diabetic retinopathy (NPDR) seen at the Ophthalmology Clinic of the University of Iowa over a period of 5 years. Patients were included if their University of Iowa medical record included blood pressure, fasting lipid profile, height, and weight. Patients were excluded if these data were not available or if they had other coexisting conditions that could also be responsible for their degree of retinopathy, such as radiation exposure or retinal venous occlusion. Diabetic patients without diabetic retinopathy and nondiabetic patients seen during the same period in the University of Iowa primary care clinics were also randomly identified for comparison. The same inclusion and exclusion criteria were applied to these latter patients.

Demographic data collected included age, sex, weight, height, hypertensive status (high blood pressure or blood pressure medication), and dyslipidemia (fasting levels of high-density lipoprotein [HDL] and triglycerides or intake of lipid-altering medications). Patients with diabetic retinopathy were divided into PDR and NPDR groups by the presence or absence of neovascularization. All data were obtained within 6 months of the retinal examination and diagnosis in the diabetic group.

\section{Metabolic syndrome}

The patient data were used to determine the presence or absence of metabolic syndrome in all patients. The 2006 International Diabetes Federation (IDF) definition of metabolic syndrome was used for this study. ${ }^{12}$ This definition requires central obesity to be present, which is defined as a waist circumference $>94 \mathrm{~cm}$ for males and $>80 \mathrm{~cm}$ for females. A body mass index (BMI) $>30 \mathrm{~kg} / \mathrm{m}^{2}$ may be used as a surrogate for increased waist circumference. Because of the retrospective nature of this study, no patient had a recorded waist circumference, and therefore, BMI was used as the primary determinant of central obesity. In addition to an elevated BMI, two of the following criteria must also be met: serum triglycerides $\geq 150 \mathrm{mg} / \mathrm{dL}$ or specific treatment for this abnormality; serum HDL $<40 \mathrm{mg} / \mathrm{dL}$ in males or $<50 \mathrm{mg} / \mathrm{dL}$ in females or specific treatment for this abnormality; systolic blood pressure $\geq 130 \mathrm{mmHg}$ or diastolic blood pressure $\geq 85 \mathrm{mmHg}$ or treatment for previously diagnosed hypertension; and the final criterion is a fasting plasma glucose $\geq 100 \mathrm{mg} / \mathrm{dL}$ or previously diagnosed type 2 diabetes.

\section{Statistical analysis}

Data were entered into a Microsoft Office Excel version 11.8 spreadsheet (Microsoft Corporation, Redmond, WA, USA). Statistical analysis was performed using SAS version 9.2 (Cary, NC). The difference in mean of continuous variables, such as age and BMI, between subgroups was compared using the analysis of variance (or Kruskal-Wallis test, if appropriate), and the difference in percentages of categorical variables, such as sex and metabolic syndrome, between subgroups was compared using the Fisher's exact test. The comparison of the mean number of components of metabolic syndrome between the subgroups was performed using Kruskal-Wallis test. 
The association between diabetic retinopathy and metabolic syndrome, along with the components of metabolic syndrome, was calculated as the odds ratio (OR) and 95\% confidence interval (CI) using age- and sex-adjusted logistic regression model. $P$-values $<0.05$ were considered statistically significant.

\section{Results}

Four hundred patients were identified in our study. Among these, there were 300 patients with diabetes, of whom 100 had no diabetic retinopathy, 100 had NPDR, and 100 had PDR. In addition, 100 nondiabetic control subjects who met the inclusion criteria were included. There was no significant difference in sex $(P=0.23)$ among the different groups of patients that were analyzed. There was a small difference in the age among the different groups, whereby PDR patients had an average age of 52.6 \pm 11.2 years compared to nondiabetic patients, who had an average age of $58.8 \pm 11.4$ years $(P=0.001)$ (Table 1).

We determined how many subjects met the individual criteria for metabolic syndrome (Figure 1). In addition, an age- and sex-adjusted logistic regression model was used to determine the ORs for the association between diabetes and metabolic syndrome (Table 2). Of the 300 patients with diabetes, 69.3\% (208/300) met the criteria for metabolic syndrome, whereas only $27.0 \%$ (27/100) of the nondiabetic patients met the criteria. This difference was statistically significant $(P<0.0001)(\mathrm{OR}=6.28 ; 95 \% \mathrm{CI}$ : 3.76-10.49; $P<0.0001$ ) (Figure 1 and Table 2). Among patients with diabetes, the presence of diabetic retinopathy was not associated with a higher prevalence of metabolic syndrome; metabolic syndrome was observed in $67.5 \%$ (135/200) of patients with retinopathy and 73\% (73/100) of diabetics without retinopathy $(P=0.36)(\mathrm{OR}=0.77 ; 95 \% \mathrm{CI}$ : $0.45-1.32$; $P=0.34$ ) (Figure 1 and Table 2). In addition, the severity of diabetic retinopathy was not associated with metabolic syndrome: the prevalence of metabolic syndrome was $72 \%$ $(72 / 100)$ in patients with NPDR compared to a prevalence of $63 \%(63 / 100)$ among patients with the more severe form of retinopathy, namely, $\mathrm{PDR}(P=0.23)(\mathrm{OR}=0.70 ; 95 \%$ CI: $0.38-1.30 ; P=0.26$ ) (Figure 1 and Table 2 ).
Each of the criteria for metabolic syndrome was examined individually for its impact on the presence of diabetes (Figure 1). Compared to nondiabetic patients, all of the components of metabolic syndrome were predictive of diabetes, including obesity ( $70 \%$ vs $34 \%, P<0.0001)$, hypertension (93.3\% vs 70\%, $P<0.0001$ ), elevated triglycerides ( $82 \%$ vs $57 \%, P<0.0001)$, low HDL (73.7\% vs $40 \%, P<0.0001)$, and fasting glucose $(100 \%$ vs $35.1 \%, P<0.0001)$ (Figure 1$)$. After adjusting for age and sex with a logistic regression model, the presence of hypertension was the most important predictor of having diabetes $(\mathrm{OR}=8.30,95 \% \mathrm{CI}: 4.21-16.33$ ) (Table 2). The next most important factor in predicting diabetes was the presence of metabolic syndrome $(\mathrm{OR}=6.28 ; 95 \%$ CI: 3.76-10.49), which was followed by HDL (OR $=6.05$, 95\% CI: 3.60-10.16), BMI (OR =4.58, 95\% CI: 2.81-7.46), and triglycerides ( $\mathrm{OR}=3.64,95 \% \mathrm{CI}: 2.18-6.07)$.

The individual components of metabolic syndrome were then evaluated for an association with the presence and severity of diabetic retinopathy (Figure 1 and Table 2). Among the components, only hypertension was observed more frequently in patients with PDR compared to patients with NPDR (OR =4.40; 95\% CI: 1.02-18.92; $P=0.047)$, and this relationship was only seen after adjusting for age and sex (Figure 1 vs Table 2). There was a trend toward elevated systolic blood pressure being predictive of diabetic retinopathy compared to diabetics without retinopathy $(P=0.043)$ (Table 3), although the prevalence of hypertension was no different between patients with and without retinopathy when controlled for the usage of antihypertensive agents, age, and sex (OR $=1.82 ; 95 \%$ CI: $0.71-4.67 ; P=0.21)$ (Table 2). The rest of the components of metabolic syndrome, including obesity, elevated triglycerides, low HDL, and fasting glucose, were seen in equal prevalence among diabetics with and without diabetic retinopathy and among diabetics with NPDR and PDR (Figure 1, Tables 2 and 3).

The average number of metabolic syndrome components was compared among the groups (Table 4). Diabetic patients had a mean of $3.91 \pm 1.0$ components, which was significantly higher than nondiabetic patients, who had a mean of $2.5 \pm 1.4$ components $(P<0.0001)$. After excluding

Table I Patient demographics

\begin{tabular}{lllll}
\hline & No DM & DM, no DR & NPDR & PDR \\
\hline Subjects, $n$ & 100 & 100 & 100 & 100 \\
Age*, years (SD) & $58.8(11.4)$ & $55.7(12.1)$ & $57.6(11.4)$ & $52.6(11.2)$ \\
Sex,$\%$ male & $46 \%$ & $54 \%$ & $60 \%$ & $50 \%$ \\
\hline
\end{tabular}

Notes: *Analysis of variance: $P=0.001$ for age; 'Fisher's exact test: $P=0.23$ for sex.

Abbreviations: DM, diabetes mellitus; DR, diabetic retinopathy; NPDR, nonproliferative diabetic retinopathy; PDR, proliferative diabetic retinopathy; SD, standard deviation. 


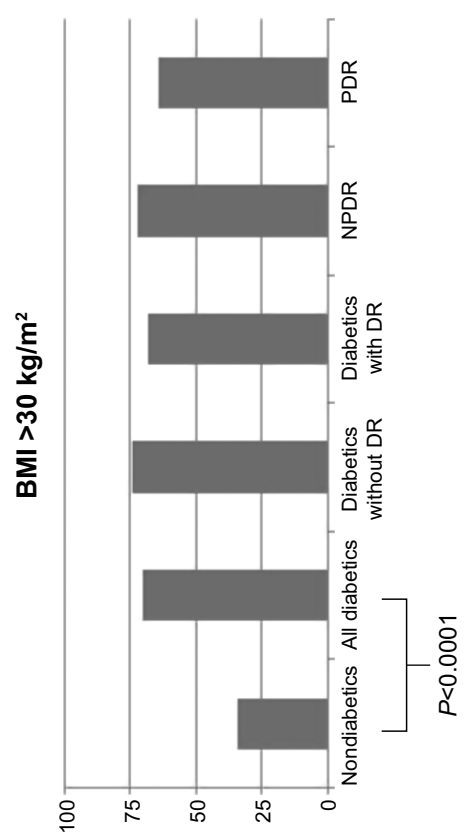

(\%)

słuə!̣ed to әбеłиәэләd

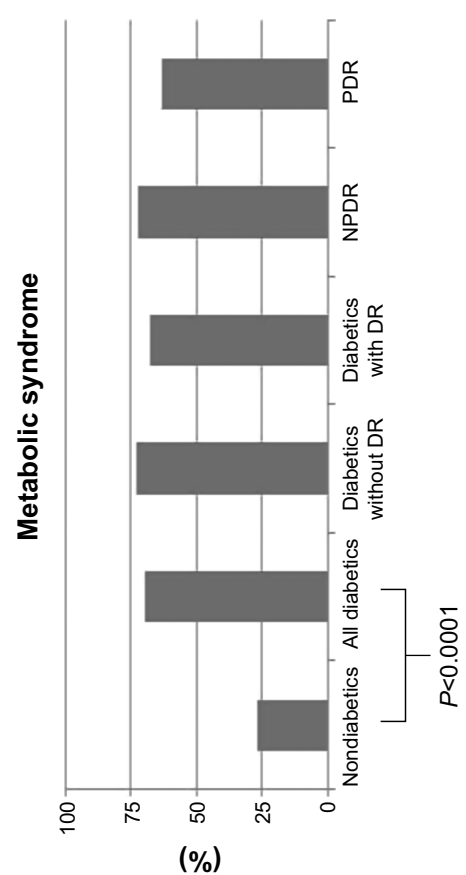

sұuə!̣ed to әбеұиәэләd
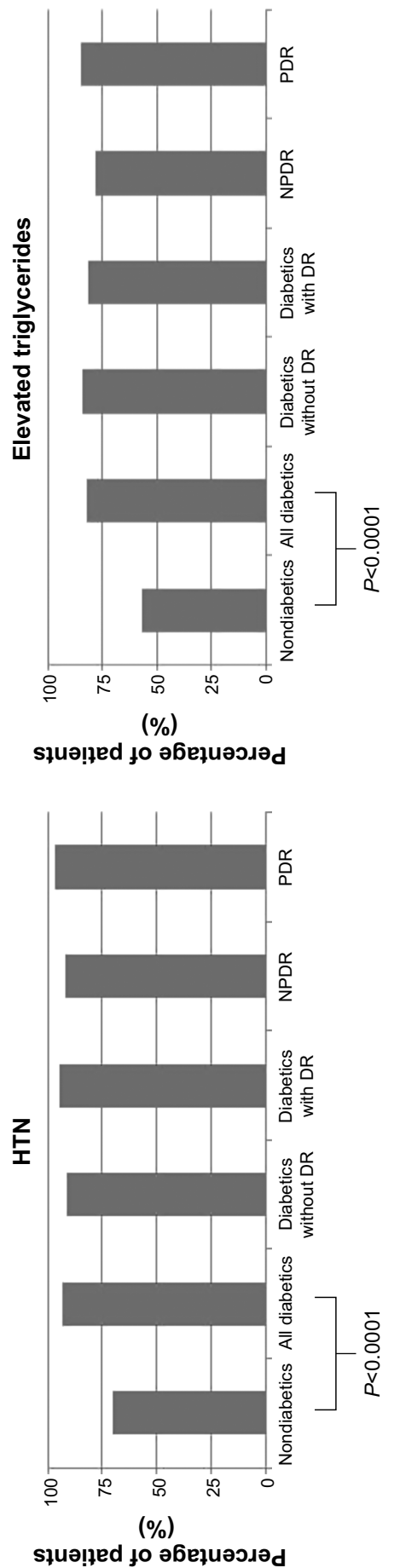
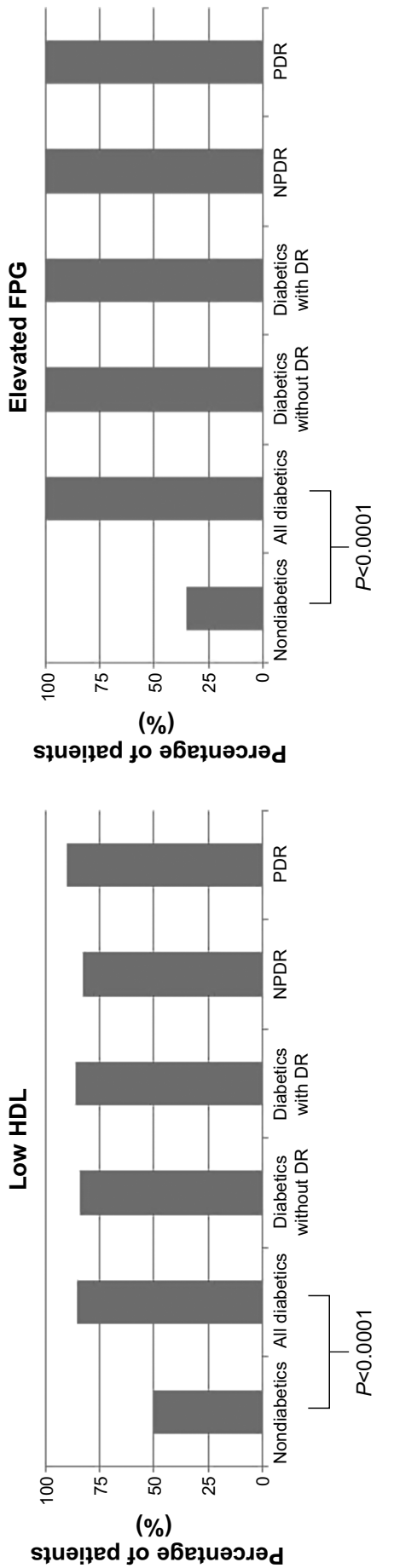
Table 2 Age- and sex-adjusted logistic regression model for metabolic syndrome and its components

\begin{tabular}{|c|c|c|c|}
\hline & Diabetes* & Diabetic retinopathy ${ }^{\dagger}$ & Severe diabetic retinopathy $\ddagger$ \\
\hline Metabolic syndrome & $\begin{array}{l}\text { OR }=6.28 ; 95 \% \text { Cl: } 3.76-10.49 \\
P<0.00 I\end{array}$ & $\begin{array}{l}\mathrm{OR}=0.77 ; 95 \% \mathrm{Cl}: 0.45-\mathrm{I} .32 \\
P=0.34\end{array}$ & $\begin{array}{l}\mathrm{OR}=0.70 ; 95 \% \mathrm{Cl}: 0.38-1.30 \\
P=0.26\end{array}$ \\
\hline BMI & $\begin{array}{l}\mathrm{OR}=4.58 ; 95 \% \mathrm{Cl}: 2.8 \mathrm{I}-7.46 \\
P<0.00 \mathrm{I}\end{array}$ & $\begin{array}{l}\text { OR }=0.75 ; 95 \% \text { Cl: } 0.44-1.28 \\
P=0.29\end{array}$ & $\begin{array}{l}\text { OR }=0.74 ; 95 \% \text { Cl: } 0.40-1.37 \\
P=0.34\end{array}$ \\
\hline Hypertension & $\begin{array}{l}\mathrm{OR}=8.30 ; 95 \% \mathrm{Cl}: 4.2 \mathrm{I}-16.33 \\
P<0.00 \mathrm{I}\end{array}$ & $\begin{array}{l}\mathrm{OR}=1.82 ; 95 \% \mathrm{Cl}: 0.7 \mathrm{I}-4.67 ; \\
P=0.2 \mathrm{I}\end{array}$ & $\begin{array}{l}\mathrm{OR}=4.40 ; 95 \% \mathrm{Cl}: \mathrm{I} .02-18.92 \\
P=0.047\end{array}$ \\
\hline Hyperlipidemia & $\begin{array}{l}\mathrm{OR}=6.05 ; 95 \% \mathrm{Cl}: 3.60-10.16 \\
P<0.00 \mathrm{I}\end{array}$ & $\begin{array}{l}O R=1.21 ; 95 \% \text { Cl: } 0.62-2.38 \\
P=0.57\end{array}$ & $\begin{array}{l}\mathrm{OR}=1.87 ; 95 \% \mathrm{Cl}: 0.79-4.42 \\
P=0.16\end{array}$ \\
\hline Triglycerides & $\begin{array}{l}\mathrm{OR}=3.64 ; 95 \% \mathrm{Cl}: 2.18-6.07 \\
P<0.00 \mathrm{I}\end{array}$ & $\begin{array}{l}\mathrm{OR}=0.84 ; 95 \% \mathrm{Cl}: 0.44-\mathrm{I} .60 \\
P=0.60\end{array}$ & $\begin{array}{l}O R=1.88 ; 95 \% \text { Cl: } 0.88-4.01 ; \\
P=0.10\end{array}$ \\
\hline
\end{tabular}

Notes: *Diabetics compared to nondiabetics; †Diabetics with diabetic retinopathy compared to diabetics without retinopathy; ${ }^{\ddagger}$ Diabetics with proliferative diabetic retinopathy compared to diabetics with nonproliferative diabetic retinopathy.

Abbreviations: $\mathrm{BMI}$, body mass index; $\mathrm{Cl}$, confidence interval; $\mathrm{OR}$, odds ratio.

diabetes as a component, diabetic patients had a mean of $2.91 \pm 0.98$ components, which was still significantly higher than nondiabetic patients $(P=0.004)$. However, there was no significant difference in the number of components among diabetic patients without diabetic retinopathy (3.92 \pm 1.0$)$, NPDR (3.89 \pm 1.0$)$, and PDR (3.93 \pm 0.9$)(P=0.97)$.

\section{Discussion}

Although metabolic syndrome is clearly a risk factor for macrovascular disease, its association with microvascular disease such as diabetic retinopathy is unclear. ${ }^{11,18}$ In our study, we found no association between metabolic syndrome and the prevalence of diabetic retinopathy. In fact, none of the components of metabolic syndrome, including obesity, hypertension, hyperlipidemia, triglycerides, or fasting glucose, were found to be risk factors for the presence of diabetic retinopathy in our study, although there was a trend of elevated systolic blood pressure being more prevalent among patients with diabetic retinopathy. A recent cross-sectional study assessing the prevalence of diabetic retinopathy in the USA identified male sex, hemoglobin Alc, duration of diabetes, hypertension, and insulin use as risk factors for the development of diabetic retinopathy. ${ }^{23}$ Interestingly, there was no association between BMI and diabetic retinopathy in that study. This supports our observation of a lack of association between metabolic syndrome and diabetic retinopathy because the single required and most important attribute for metabolic syndrome according to the IDF definition is central obesity as defined by an increase in BMI or enlarged waist circumference.

While prior studies support our finding of a lack of association between metabolic syndrome and diabetic retinopathy, ${ }^{21,22}$ some other studies have suggested an association between the two diseases. ${ }^{13,19,20}$ It is possible that using the IDF criteria instead of different criteria for identifying metabolic syndrome may account for some of the differences between our study and others that did identify an association between metabolic syndrome and retinopathy. For instance,

Table 3 Average values for metabolic syndrome components

\begin{tabular}{|c|c|c|c|c|c|}
\hline & No DM & DM, no DR & NPDR & PDR & $P$-value \\
\hline $\mathrm{BMI} \pm \mathrm{SD}\left(\mathrm{kg} / \mathrm{m}^{2}\right)$ & $28.7 \pm 7.0$ & $36.2 \pm 10.0$ & $34.9 \pm 8.1$ & $33.8 \pm 8.6$ & $<0.001$ \\
\hline $\begin{array}{l}\text { Systolic blood } \\
\text { pressure } \pm \mathrm{SD}(\mathrm{mmHg})\end{array}$ & $131.5 \pm 18.3$ & $129.5 \pm 17.2$ & $134.4 \pm 18.5$ & $136.9 \pm 19.7$ & 0.043 \\
\hline $\begin{array}{l}\text { Diastolic blood } \\
\text { pressure } \pm \mathrm{SD}(\mathrm{mmHg})\end{array}$ & $76.7 \pm 11.9$ & $74.9 \pm 9.0$ & $71.7 \pm 10.1$ & $74.1 \pm I I .4$ & 0.010 \\
\hline $\mathrm{HDL} \pm \mathrm{SD}(\mathrm{mg} / \mathrm{dL})$ & $58.1 \pm 16.2$ & $46.2 \pm 17.6$ & $43.4 \pm 13.1$ & $45.3 \pm 14.1$ & $<0.001$ \\
\hline Triglycerides \pm SD (mg/dL) & $128.1 \pm 73.3$ & $190.9 \pm 199.9$ & $173.5 \pm 180.8$ & $167.5 \pm 121.8$ & 0.020 \\
\hline $\mathrm{FPG}^{*} \pm \mathrm{SD}(\mathrm{mg} / \mathrm{dL})$ & $96.9 \pm 14.1 ; n=94$ & $164.6 \pm 77.5$ & $176.4 \pm 82.9$ & $164.1 \pm 80.2$ & $<0.001$ \\
\hline $\begin{array}{l}\% \text { patients taking } \\
\text { antihypertensive medication }\end{array}$ & $53 \%$ & $84 \%$ & $92 \%$ & $93 \%$ & $<0.001$ \\
\hline $\begin{array}{l}\% \text { patients taking } \\
\text { antihyperlipidemic medication }\end{array}$ & $40 \%$ & $71 \%$ & $71 \%$ & $79 \%$ & $<0.001$ \\
\hline
\end{tabular}

Note: *Fasting glucose was not available for six patients in the no-DM group.

Abbreviations: BMI, body mass index; DM, diabetes mellitus; DR, diabetic retinopathy; FPG, fasting plasma glucose; HDL, high-density lipoprotein; NPDR, nonproliferative diabetic retinopathy; PDR, proliferative diabetic retinopathy; SD, standard deviation. 
Table 4 Frequency of metabolic syndrome components

\begin{tabular}{lllll}
\hline $\begin{array}{l}\text { Number of metabolic } \\
\text { syndrome components }\end{array}$ & \multicolumn{2}{l}{ Frequency of components } & NPDR \\
\cline { 2 - 5 } & No DM* & DM, no DR & 0 & PDR \\
\hline 0 & $8 / 94$ & 0 & $3 / 100$ & 0 \\
1 & $18 / 94$ & $3 / 100$ & $9 / 100$ & $1 / 100$ \\
2 & $22 / 94$ & $6 / 100$ & $15 / 100$ & $4 / 100$ \\
3 & $19 / 94$ & $18 / 100$ & $42 / 100$ & $39 / 100$ \\
4 & $21 / 94$ & $42 / 100$ & $31 / 100$ & $30 / 100$ \\
5 & $6 / 94$ & $31 / 100$ & $72 / 100$ & $63 / 100$ \\
\hline Metabolic syndrome & $27 / 100^{\dagger}$ & $73 / 100$ & &
\end{tabular}

Notes: *Fasting glucose was not available for six patients in the no-DM group; ${ }^{\dagger} P<0.00$ I.

Abbreviations: DM, diabetes mellitus; DR, diabetic retinopathy; NPDR, nonproliferative diabetic retinopathy; PDR, proliferative diabetic retinopathy.

Costa et $\mathrm{al}^{19}$ found an association between metabolic syndrome and retinopathy using the World Health Organization criteria, which requires the presence of insulin resistance or diabetes, along with the presence of two or more of the following criteria: hypertension, obesity, hyperlipidemia, and microalbuminemia. In contrast, the IDF definition places obesity as the required criterion, and therefore our findings of a lack of an association between metabolic syndrome and retinopathy may be a reflection of there being no association between obesity and retinopathy. The IDF definition, which places the highest emphasis on obesity, is the most widely accepted definition because the pathogenesis of metabolic syndrome is thought to result primarily from obesity; ${ }^{24}$ therefore, this definition is likely the best to determine the impact of metabolic syndrome on retinopathy.

Our study was the first to specifically look at metabolic syndrome and its association with the severity of diabetic retinopathy. We demonstrated that there was no relationship between metabolic syndrome and increasing severity of diabetic retinopathy as evidenced by the lack of difference in the prevalence of metabolic syndrome between diabetics with nonproliferative retinopathy, and those with the more severe, proliferative retinopathy. When comparing risk factors for severity of diabetic retinopathy, among the components of metabolic syndrome, only hypertension was found to be associated with more severe diabetic retinopathy. Hypertension has also been reported as a risk factor for the severity of diabetic retinopathy in other studies. ${ }^{25-27}$

The lack of an association between metabolic syndrome and diabetic retinopathy was somewhat surprising because metabolic syndrome has been associated with other vascular diseases. The pathologic effect of metabolic syndrome is thought to cause increased inflammation and oxidative stress, ${ }^{28}$ which could potentially be more pronounced in large-vessel disease than in microvascular disease such as that involving the retina. This provides a potential explanation for the lack of association between metabolic syndrome and diabetic retinopathy in our study. Indeed, despite multiple studies consistently showing a strong association between metabolic syndrome and cardiovascular disease, the connection between metabolic syndrome and microvascular disease, such as renal disease and retinopathy, has either been lacking or reported with a weaker association compared to cardiovascular disease. ${ }^{11,18,29}$ In fact, one study ${ }^{30}$ demonstrated a negative correlation between metabolic syndrome and the stage of renal failure.

Limitations of our study could include its retrospective design and sample size. A larger sample size could potentially uncover more associations between the components of metabolic syndrome and diabetic retinopathy. Because waist circumference is not routinely measured at the University of Iowa, we used BMI as a surrogate measure of abdominal adiposity. While this is acceptable according to the IDF definition, it may lead to some underestimation of the prevalence of obesity in our population. Moreover, in addition to serum lipids and systemic blood pressure measurements, we accepted the use of blood pressure- and lipid-lowering medications as criteria, which is part of the IDF criteria but has not been used in all other studies. Lastly, our study did not control for the exact duration of diabetes or insulin dependence, largely because these data were not available in patients referred solely for retinal eye examination and treatment. Recent studies indicating that longer duration of diabetes and insulin dependence are linked to the presence and severity of diabetic retinopathy despite a lack of association between BMI and retinopathy suggests that these latter two variables would not be expected to influence our results on the prevalence of metabolic syndrome. ${ }^{23}$

\section{Conclusion}

In summary, our study indicates that metabolic syndrome and obesity are not significant risk factors for the development 
or severity of diabetic retinopathy in our study population. Although all the factors of metabolic syndrome are important to control for the general health of the patient, our study suggests that obesity and hyperlipidemia do not play a role in the development of diabetic retinopathy, while hypertension likely has an influence on the severity of diabetic retinopathy. Ocular examinations and surgical therapies directed to the eye remain the primary focus for ophthalmologists.

\section{Acknowledgments}

This material was presented at the Annual Meeting of the Association for Research in Vision and Ophthalmology, Fort Lauderdale, FL, USA, in May 2011. This study received financial support from the voluntary organization Research to Prevent Blindness. The funding organization had no role in the design or conduct of this research.

\section{Disclosure}

The authors report no conflicts of interest in this work.

\section{References}

1. Williams R, Airey M, Baxter H, Forrester J, Kennedy-Martin T, Girach A. Epidemiology of diabetic retinopathy and macular oedema: a systematic review. Eye (Lond). 2004;18(10):963-983.

2. Danaei G, Finucane MM, Lu Y, et al; Global Burden of Metabolic Risk Factors of Chronic Diseases Collaborating Group (Blood Glucose). National, regional, and global trends in fasting plasma glucose and diabetes prevalence since 1980: systematic analysis of health examination surveys and epidemiological studies with 370 country-years and 2.7 million participants. Lancet. 2011;378(9785):31-40.

3. Klein R, Klein BE, Moss SE, Linton KL. The Beaver Dam Eye Study. Retinopathy in adults with newly discovered and previously diagnosed diabetes mellitus. Ophthalmology. 1992;99(1):58-62.

4. Kini MM, Leibowitz HM, Colton T, Nickerson RJ, Ganley J, Dawber TR. Prevalence of senile cataract, diabetic retinopathy, senile macular degeneration, and open-angle glaucoma in the Framingham eye study. Am J Ophthalmol. 1978;85(1):28-34.

5. Klein R, Klein BE, Moss SE, Wong TY. The relationship of retinopathy in persons without diabetes to the 15-year incidence of diabetes and hypertension: Beaver Dam Eye Study. Trans Am Ophthalmol Soc. 2006;104:98-107.

6. Wong TY, Liew G, Tapp RJ, et al. Relation between fasting glucose and retinopathy for diagnosis of diabetes: three population-based crosssectional studies. Lancet. 2008;371(9614):736-743.

7. Mitchell P, Smith W, Wang JJ, Attebo K. Prevalence of diabetic retinopathy in an older community. The Blue Mountains Eye Study. Ophthalmology. 1998;105(3):406-411.

8. Massin P, Lange C, Tichet J, et al; DESIR (Data From an Epidemiological Study on the Insulin Resistance Syndrome) Study Group. Hemoglobin A1c and fasting plasma glucose levels as predictors of retinopathy at 10 years: the French DESIR study. Arch Ophthalmol. 2011;129(2):188-195.

9. ACCORD Study Group, ACCORD Eye Study Group, Chew EY, et al. Effects of medical therapies on retinopathy progression in type 2 diabetes. N Engl J Med. 2010;363(3):233-244.

10. Lim LS, Tai ES, Mitchell P, et al. C-reactive protein, body mass index, and diabetic retinopathy. Invest Ophthalmol Vis Sci. 2010;51(9): 4458-4463.
11. Cornier MA, Dabelea D, Hernandez TL, et al. The metabolic syndrome. Endocr Rev. 2008;29(7):777-822.

12. Alberti KG, Zimmet P, Shaw J. Metabolic syndrome - a new worldwide definition. A consensus statement from the international diabetes federation. Diabet Med. 2006;23(5):469-480.

13. Metascreen Writing Committee, Bonadonna RC, Cucinotta D, Fedele D, Riccardi G, Tiengo A. The metabolic syndrome is a risk indicator of microvascular and macrovascular complications in diabetes: results from metascreen, a multicenter diabetes clinic-based survey. Diabetes Care. 2006;29(12):2701-2707.

14. Guzder RN, Gatling W, Mullee MA, Byrne CD. Impact of metabolic syndrome criteria on cardiovascular disease risk in people with newly diagnosed type 2 diabetes. Diabetologia. 2006;49(1):49-55.

15. Song SH, Hardisty CA. Diagnosing metabolic syndrome in type 2 diabetes: does it matter? QJM. 2008;101(6):487-491.

16. Weiss R, Dziura J, Burgert TS, et al. Obesity and the metabolic syndrome in children and adolescents. $N$ Engl J Med. 2004;350(23):2362-2374.

17. Cameron AJ, Magliano DJ, Zimmet PZ, Welborn T, Shaw JE. The metabolic syndrome in Australia: prevalence using four definitions. Diabetes Res Clin Pract. 2007;77(3):471-478.

18. Cull CA, Jensen CC, Retnakaran R, Holman RR. Impact of the metabolic syndrome on macrovascular and microvascular outcomes in type 2 diabetes mellitus: United Kingdom Prospective Diabetes Study 78. Circulation. 2007;116(19):2119-2126.

19. Costa LA, Canani LH, Lisboa HR, Tres GS, Gross JL. Aggregation of features of the metabolic syndrome is associated with increased prevalence of chronic complications in Type 2 diabetes. Diabet Med. 2004;21(3):252-255.

20. Abdul-Ghani M, Nawaf G, Nawaf F, Itzhak B, Minuchin O, Vardi P. Increased prevalence of microvascular complications in type 2 diabetes patients with the metabolic syndrome. Isr Med Assoc $J$. 2006;8(6):378-382.

21. Isomaa B, Henricsson M, Almgren P, Tuomi T, Taskinen MR, Groop L. The metabolic syndrome influences the risk of chronic complications in patients with type II diabetes. Diabetologia. 2001;44(9):1148-1154.

22. Raman R, Gupta A, Pal SS, et al. Prevalence of metabolic syndrome and its influence on microvascular complications in the Indian population with type 2 diabetes mellitus. Sankara Nethralaya Diabetic Retinopathy Epidemiology and Molecular Genetic Study (SN-DREAMS, report 14). Diabetol Metab Syndr. 2010;2:67.

23. Zhang X, Saaddine JB, Chou CF. Prevalence of diabetic retinopathy in the United States, 2005-2008. JAMA. 2010;304(6):649-656.

24. Eckel RH, Grundy SM, Zimmet PZ. The metabolic syndrome. Lancet. 2005;365(9468):1415-1428.

25. Chatziralli IP, Sergentanis TN, Keryttopoulos P, Vatkalis N, Agorastos A, Papazisis L. Risk factors associated with diabetic retinopathy in patients with diabetes mellitus type 2. BMC Res Notes. 2010;3:153.

26. Rani PK, Raman R, Chandrakantan A, Pal SS, Perumal GM, Sharma T. Risk factors for diabetic retinopathy in self-reported rural population with diabetes. J Postgrad Med. 2009;55(2):92-96.

27. Wang $\mathrm{S}, \mathrm{Xu} \mathrm{L}$, Jonas JB, et al. Major eye diseases and risk factors associated with systemic hypertension in an adult Chinese population: the Beijing Eye Study. Ophthalmology. 2009;116(12):2373-2380.

28. Roberts CK, Sindhu KK. Oxidative stress and metabolic syndrome. Life Sci. 2009;84(21-22):705-712.

29. Kurella M, Lo JC, Chertow GM. Metabolic syndrome and the risk for chronic kidney disease among nondiabetic adults. J Am Soc Nephrol. 2005;16(7):2134-2140.

30. Sagun G, Kantarci G, Mesci B. Frequency of cardiovascular risk factors and metabolic syndrome in patients with chronic kidney disease. Clin Med Res. 2010;8(3-4):135-141. 


\section{Publish your work in this journal}

Clinical Ophthalmology is an international, peer-reviewed journal covering all subspecialties within ophthalmology. Key topics include: Optometry; Visual science; Pharmacology and drug therapy in eye diseases; Basic Sciences; Primary and Secondary eye care; Patient Safety and Quality of Care Improvements. This journal is indexed on

Submit your manuscript here: http://www.dovepress.com/clinical-ophthalmology-journal
PubMed Central and CAS, and is the official journal of The Society of Clinical Ophthalmology (SCO). The manuscript management system is completely online and includes a very quick and fair peer-review system, which is all easy to use. Visit http://www.dovepress.com/ testimonials.php to read real quotes from published authors. 